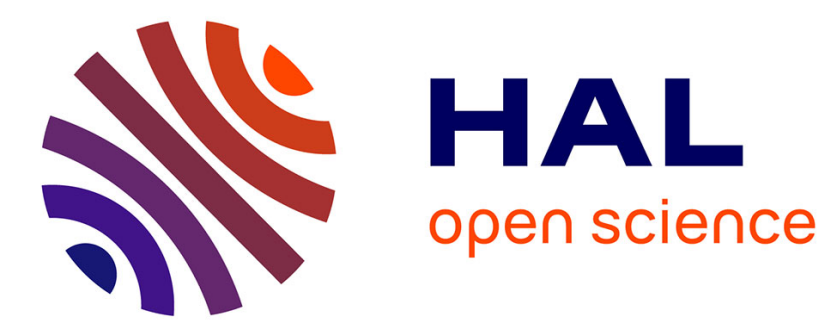

\title{
Heat and mass transfer in evaporating droplets in interaction: Influence of the fuel
}

\author{
Valérie Deprédurand, Guillaume Castanet, Fabrice Lemoine
}

\section{To cite this version:}

Valérie Deprédurand, Guillaume Castanet, Fabrice Lemoine. Heat and mass transfer in evaporating droplets in interaction: Influence of the fuel. International Journal of Heat and Mass Transfer, 2010, 53, pp.3495 - 3502. 10.1016/j.ijheatmasstransfer.2010.04.010 . hal-01570423

\section{HAL Id: hal-01570423 \\ https://hal.univ-lorraine.fr/hal-01570423}

Submitted on 29 Jul 2017

HAL is a multi-disciplinary open access archive for the deposit and dissemination of scientific research documents, whether they are published or not. The documents may come from teaching and research institutions in France or abroad, or from public or private research centers.
L'archive ouverte pluridisciplinaire HAL, est destinée au dépôt et à la diffusion de documents scientifiques de niveau recherche, publiés ou non, émanant des établissements d'enseignement et de recherche français ou étrangers, des laboratoires publics ou privés.

\section{(1)(1) $\$(0)$}

Distributed under a Creative Commons Attribution - NonCommercial - ShareAlikel 4.0 


\title{
Heat and mass transfer in evaporating droplets in interaction: Influence of the fuel
}

\author{
V. Deprédurand, G. Castanet ${ }^{*}$, F. Lemoine \\ LEMTA, CNRS, Nancy-Université, 2, Avenue de la forêt de Haye, BP 160, F-54504 Vandoeuvre-lès-Nancy, France
}

Keywords:

Evaporation

Droplets

Interaction

Laser-induced fluorescence

\begin{abstract}
A B S T R A C T
The prediction of heat and mass transfer in fuel sprays is a key issue in the design of combustors where the fuel is injected in a liquid form. The development and validation of new physical models requires reliable experimental data. This paper reports on an experimental study to characterize the Nusselt and Sherwood numbers of monodisperse droplets made of fuels having different volatilities and evaporating into flowing hot air. Simultaneous measurements of the droplet size and mean temperature allowed evaluating the heat fluxes that take part in the evaporation. The experimental Nusselt and Sherwood numbers are then compared to the case of an isolated droplet. It appears that these numbers are particularly dependent on the interactions between the droplets in a way that depends on the fuel nature.
\end{abstract}

\section{Introduction}

The evaporation of fuel sprays in internal combustion engines is well-known to have a strong influence on the pollutant emissions, ignition delays and overall combustor efficiency. When a fuel droplet enters into a high temperature environment like in a combustion chamber, the droplet is heated, evaporates and finally the fuel vapour burns, delivering the energy for propulsion. A reliable description of the heat and mass transfer in sprays is required to optimize the combustion chambers of the engines and make them fit environmental requirements in term of pollutant emissions. In a spray, the droplet dispersion is usually characterized by the Stokes number. When the Stokes number is of the order of unity, droplet clusters can be formed. In such clusters, heat and mass transfer are significantly reduced compared to an isolated droplet. If evaporation and combustion models for isolated, stagnant or moving fuel droplets are now widely available in the literature ([1-4]), the understanding of droplet-to-droplet interactions is still limited.

Studies dealing with this topic were generally based on numerical approaches and focalized on basic situations. Labowsky [5] and Marberry et al. [6] used the point sources method to determine the burning rates of stagnant droplets in finite arrays containing up to eight symmetrically arranged monodisperse droplets. Particle interactions were shown to be a function of particle size, number density and geometry of the array. Correction factors from which multiple particle burning rates can be calculated from single particle burning rates were established. Chiang and Sirignano $[7,8]$ were able to take into account the effect of the droplet motion by

\footnotetext{
* Corresponding author. Tel.: +33 38359 5552; fax: +33 383595551.

E-mail address: guillaume.castanet@ensem.inpl-nancy.fr (G. Castanet).
}

performing a comprehensive numerical study of two and three evaporating droplets moving together. Their computation included: the effects of variable thermophysical properties, transient heating and internal circulation in the liquid phase, boundary-layer blowing, moving interface due to surface regression. They underlined the effect of the droplet spacing and the subsequent modifications of the Nusselt and Sherwood numbers. Imaoka and Sirignano $[9,10]$ considered the vaporization of three-dimensional droplet arrays. Burning rates were computed and correlated with the number of droplets, average droplet size and average spacing for the array through one similarity parameter for arrays as large as 1000 droplets. Total array vaporization rates were found to be maximized at a specific droplet number density that depends on liquid volume within the array.

From an experimental point of view, it is generally difficult to separate the relative influences of the environmental and injection parameters. These problems are not encountered for linearly streaming monodisperse droplets. The size, velocity, temperature and spacing of the droplets can be adjusted separately at the injection, where as the ambient conditions can be controlled [11]. Sangiovanni and Kesten [12] were perhaps the first to investigate the effects of droplet interaction on the ignition time for linear droplet streams injected into a hot gas environment. They noticed that a closer spacing of the droplets enhances the heat and mass diffusion from the flame region. Sangiovanni and Labowsky [13] reported measurements of the droplet lifetime under similar conditions. They found that the classical "D2-Law" is not strictly applicable to interacting droplets due to the transient nature of this interaction. Among the experimental studies available in the literature, Virepinte et al. [14] and Castanet et al. [15] carried out experiments on periodically arranged monosized ethanol droplets 


\section{Nomenclature}

$\begin{array}{ll}\text { Symbol } & \text { Quantity (SI Unit) } \\ a & \text { Thermal diffusivity }\left(\mathrm{m}^{2} / \mathrm{s}\right) \\ B_{M} & \text { Mass transfer Spalding number } \\ B_{T} & \text { Thermal transfer Spalding number } \\ C & \text { Distance parameter } \\ C_{0} & \text { Tracer concentration }(\mathrm{mol} / \mathrm{L}) \\ C_{p} & \text { Specific heat }(\mathrm{J} / \mathrm{kg} / \mathrm{K}) \\ D & \text { Droplet diameter }(\mathrm{m}) \\ D_{g} & \text { Molecular diffusivity of the vapour }\left(\mathrm{m}^{2} / \mathrm{s}\right) \\ f & \text { Frequency of the droplets }\left(\mathrm{s}^{-1}\right) \\ I & \text { Light intensity }\left(\mathrm{W} / \mathrm{m}^{2}\right) \\ K & \text { A constant or the evaporation rate }\left(\mathrm{m}^{2} / \mathrm{s}\right) \\ L e & \text { Lewis number } \\ L_{v} & \text { Latent heat of vaporization }(\mathrm{J} / \mathrm{kg}) \\ m & \text { Droplet mass }(\mathrm{kg}) \\ \dot{m} & \text { Fuel vapour flow rate }(\mathrm{kg} / \mathrm{s}) \\ N u & \text { Nusselt number } \\ P r & \text { Prandtl number } \\ P & \text { Pressure (Pa) } \\ Q_{L} & \text { Heat flux entering into the droplet }(\mathrm{W}) \\ R & \text { Droplet radius }(\mathrm{m}) \\ R e & \text { Droplet Reynolds number } \\ S h & \text { Sherwood number }\end{array}$

$\begin{array}{ll}S c & \text { Schmidt number } \\ T & \text { Temperature }(\mathrm{K}) \\ t & \text { Time }(\mathrm{s}) \\ V & \text { Droplet velocity }(\mathrm{m} / \mathrm{s}) \\ Y & \text { Fuel vapour mass fraction } \\ & \\ \text { Greek symbols } \\ \Phi_{C} & \text { Convective heat flux }(\mathrm{W}) \\ \Phi_{\text {vap }} & \text { Vaporization heat flux }(\mathrm{W}) \\ \lambda & \text { Thermal conductivity }(\mathrm{W} / \mathrm{m} / \mathrm{K}) \\ \mu & \text { Dynamic viscosity }(\mathrm{PI}) \\ \rho & \text { Specific density }\left(\mathrm{kg} / \mathrm{m}^{3}\right)\end{array}$

\section{Subscripts}

g Gas phase

$l \quad$ Fuel liquid phase

ref Reference state

$S \quad$ Surface condition

$i \quad$ First point of measurement at the entrance in the enclo-

sure

amb Conditions in the free stream far from the droplets

0 Isolated droplet without the Stefan flow placed in a laminar flame produced by the combustion of their own vapour. Their results emphasize that the influence of the droplet spacing on their evaporation rate is particularly important when the distance between the droplets varies from 2 to 8 times their diameter. Similar observations can be found in Castanet et al. [16] and Atthasit et al. [17] in the case of droplets evaporating in the thermal boundary layer of a heated plate. Castanet et al. [15] and Atthasit et al. [17] suggested separately a correlation based on a correction of the Sherwood and Nusselt numbers of the isolated droplet. They assumed that the distance parameter (distance between the droplets divided by their diameter) was sufficient to account for their observations. Their investigations were limited to a relatively narrow range of experimental conditions in term of Reynolds, Spalding and Lewis numbers was explored. Having considered in one case: ethanol droplets evaporating in a flame, and in the other case: droplets evaporating in the vicinity of a heated plate, Castanet et al. [15] and Atthasit et al. [17] did not obtain similar corrections based on the distance parameter.

Nonetheless, their corrections proved to be rather appropriate to account for the evaporation of linearly streaming droplets in many situations: acetone droplets evaporating and cooling at moderate ambient temperatures [18], ethanol and acetone droplets heating and evaporating in a hot air flow or in a flame [19], and with some limitations bicomponent droplets made of acetone and ethanol [20].

Recently, Deprédurand et al. [21] performed experiments on ethanol/3-pentanone bicomponent droplets evaporating into a heated enclosure under different ambient temperatures ranging from 20 to $360{ }^{\circ} \mathrm{C}$. Results revealed that the before-mentioned correlation fails to describe this situation. From the comparison between these fuels having different volatilities, the authors stressed the importance of parameters related to the fuel nature to describe the effect of droplet-to-droplet interactions on heat and mass transfer.

The purpose of this study is to give some insight into these effects linked to the fuel nature. To that end, six fuels having different volatilities (acetone, ethanol, 3 -pentanone, $n$-heptane, $n$-decane and $n$-dodecane) have been tested. Monodisperse chains of droplets, streaming linearly, are injected into a temperature controlled enclosure. The size and temperature of the droplets are measured using optical techniques. Data are then processed to estimate Nusselt and Sherwood numbers. Finally, the derived Nusselt and Sherwood numbers are compared to their counterparts for an isolated droplet, for which well-established models already exist, in order to quantify the effect of the droplet interactions.

\section{Experimental set-up and measurement techniques}

\subsection{Experimental set-up}

A monodisperse droplet stream is generated by disintegration of a liquid jet undergoing vibrations from a piezoceramic [11]. The liquid temperature is regulated in the injector body and the temperature is measured accurately close to the injection point with a $\mathrm{K}$ type thermocouple. The droplets are then injected into an enclosure fed with hot air coming from an electrical heater (power: $0.8 \mathrm{~kW}$ ) (Fig. 1). The air flowrate can be adjusted and its value is measured upstream from the heater. In order to limit the thermal losses, a resistive electrical wire is inserted within the enclosure wall so that the wall temperature can be regulated to match the one of the entering air. Temperature up to $400{ }^{\circ} \mathrm{C}$ can be reached. Additionally, glass windows have been mounted in the wall to have optical accesses. Destabilization of the droplet stream by the air motion can be a critical issue in this experiment. The air velocity is therefore maintained between 0.1 and $0.3 \mathrm{~m} / \mathrm{s}$ and the air flow is quietened by forcing it to go through metallic foam and a drilled wall. The problem of vapour saturation must be considered carefully due to the moderate air blowing and the finite dimension of the chamber which has an inner diameter of $10 \mathrm{~cm}$ and a height of $14 \mathrm{~cm}$. An estimate of the diffusion length $L$ can be obtained considering a diffusivity $\alpha=10^{-5} \mathrm{~m}^{2} / \mathrm{s}$ and a diffusion duration $t$ equal to $1 \mathrm{~s}$. The latter corresponds to the time for a particle to be transported by the air stream through the enclosure. $L=\sqrt{\alpha t}$ is about $3 \mathrm{~mm}$ which is negligible compared to the inner radius of the enclosure. This ensures non-saturated conditions. 


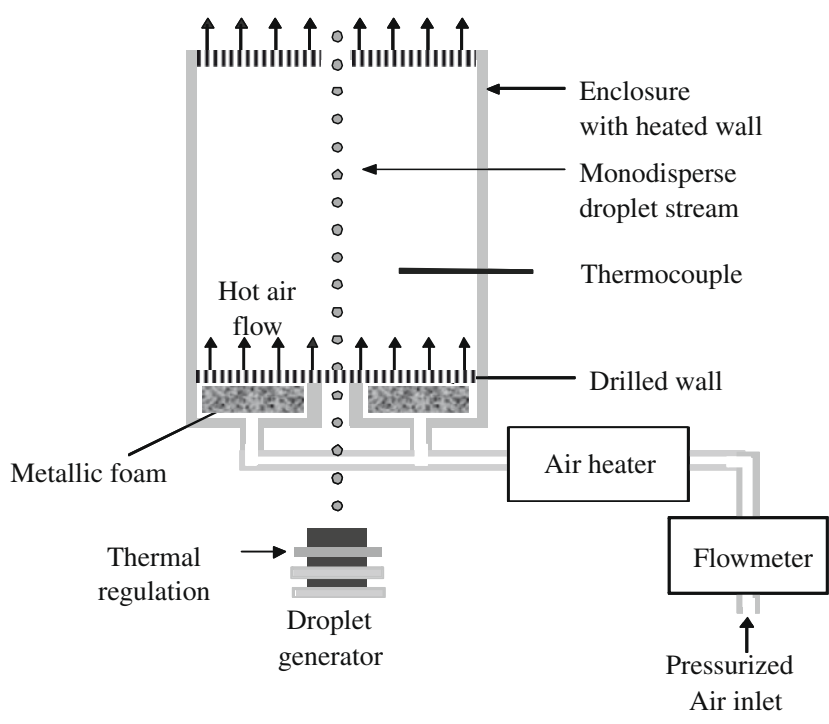

Fig. 1. Layout of the heated enclosure and the droplet generator.

\subsection{Droplet temperature measurement}

Only the main outlines of the two-colour laser-induced fluorescence technique (2cLIF) are given in this section. A comprehensive survey of the method can be found in [22-24]. The fluorescent tracer used presently is pyrromethene 597-C8 which has a fluorescence that can be easily induced by the green line $(514.5 \mathrm{~nm})$ of the argon ion laser. The ratio of the fluorescence intensity detected on two spectral bands is a function of the temperature regardless laser intensity, time-dependant tracer concentration, and measurement volume. Practically, the excitation volume of the fluorescence is formed by the beam system of a Laser Doppler Anemometer (LDA) (Fig. 2 a) allowing the simultaneous measurement of the droplet velocity. In the present optical layout, this volume corresponds to an ellipsoid of revolution which is $1500 \mu \mathrm{m}$ long in the direction of the beams and $150 \mu \mathrm{m}$ long transversally. The measurement system provides the volume averaged temperature with an accuracy estimated at $\pm 1{ }^{\circ} \mathrm{C}$. An interesting feature of pyrromethene $597-\mathrm{C} 8$ relates to its temperature sensitivity $\beta(\lambda)$ that is almost unchanged when dissolved into any of the selected fuels (acetone, ethanol, 3-pentanone, $n$-heptane, $n$-decane and $n$-dodecane) [25].Therefore, identical spectral bands of detection [540; $560 \mathrm{~nm}$ ] and [590; $610 \mathrm{~nm}$ ] can be selected without detriment to the measurement accuracy.

\subsection{Measurement of the droplet size}

Characterization of the droplet size reduction is necessary to determine the evaporation of the droplets. Forward scattering interferometry (FSI) is used to determine the droplet diameter with a good accuracy. This measurement technique is based on the interaction between a spherical droplet and a laser beam [26]. A beam issuing from an argon ion laser is focused on a droplet (Fig. 2b). Interferences between rays of order 0 and 1 are generated in the forward direction.

It is also possible to determine droplet size variations using a phase Doppler system (PDA) as presented by Castanet et al. [15]. However, the FSI technique is particularly well adapted to the case of monodisperse droplet streams, because of the high frequency of the droplet passages that makes the fringe pattern appear stationary. Measurement of the angular interfringe near the forward scattering angle of $30^{\circ}$ enables to determine the droplet diameter

(a)

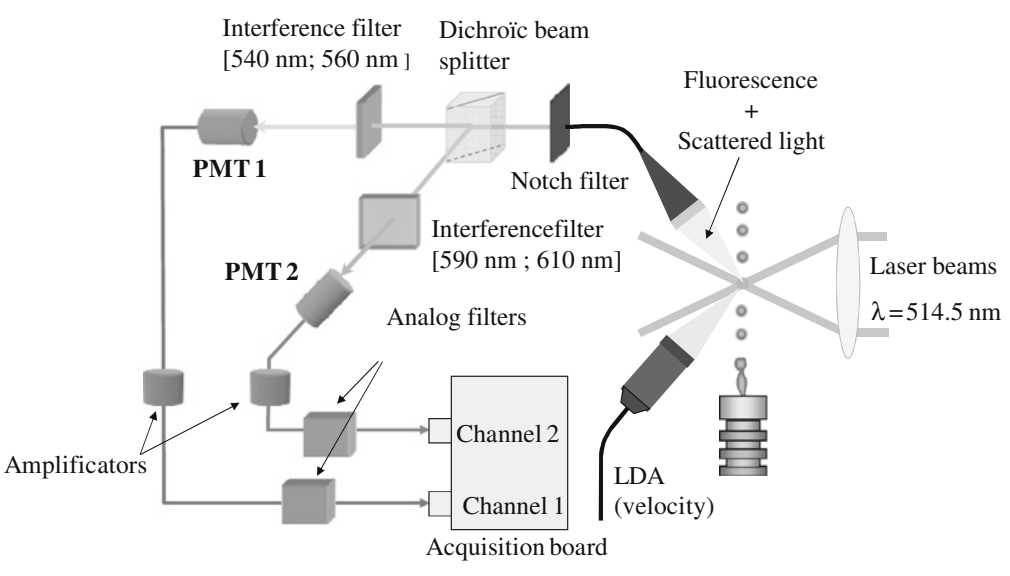

(b)

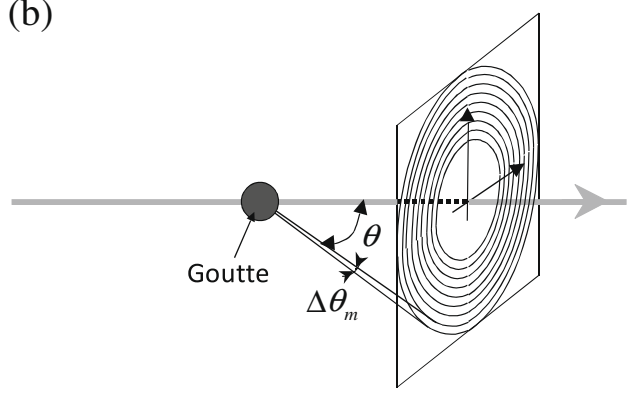

(c)

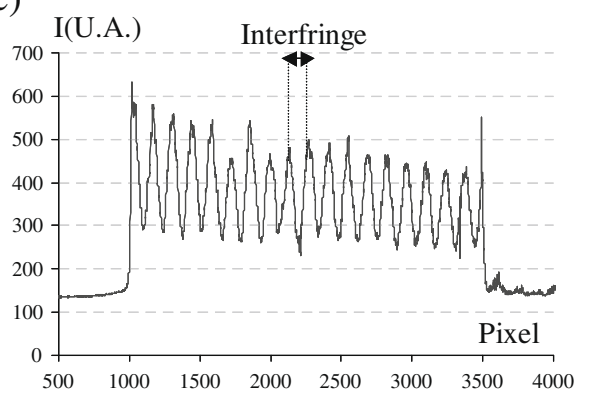

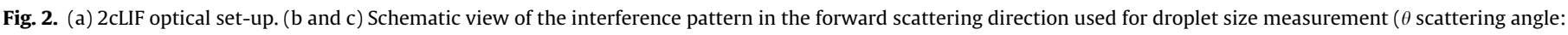
$\Delta \theta_{m}$ angular interfringe). 
within $\pm 0.5 \mu \mathrm{m}$ with a very limited sensitivity to the droplet refractive index [27].

Image of the spatial intensity distribution is formed on the linear sensor chipset of a CCD camera (4096 pixels) (Fig. 2b and c). The angular interfringe is measured between two interference maxima in order to derive the droplet size as suggested by Frohn and Roth [11]. The method is relatively easy to implement since long shutter time of the camera can be used to obtain sufficient light intensity. It can be applied over a rather wide range of sizes even if the fringe spacing becomes shorter when increasing the droplet diameter. In contrast, effects of trajectory dependent scattering in the PDA technique are always a concern when droplet sizes are in the order of the probe volume [28].

\section{Droplet size and temperature evolutions}

The temperature and size of the droplets were measured for a large set of aerothermal conditions and for all the aforementioned fuel species. The ambient temperature in the enclosure was fixed at $370{ }^{\circ} \mathrm{C}$ during all the experiments. The temperature, velocity and diameter of the droplet are measured simultaneously at several measurement positions in the enclosure. The periodicity of the droplet stream and its steadiness allows converting the droplet distance from the injector into time. In the following, the origin of time is fixed at the first measurement position at the entrance of the enclosure. The time elapsed from this origin to the current measurement point is determined from the velocity measured by LDA [15]. Thus, the droplet diameter and temperature evolutions can be monitored as a function of time.

To highlight the influence of the fuel nature, droplet streams made of the different fuels were injected under conditions as close as possible. Due to differences in the atomization process, the liquid pressure and temperature in the injector, as well as the piezoceramic frequency have to be adjusted from one fuel to another. Nevertheless, as indicated in Table 1, slight differences remain at the first measurement position in the enclosure.

The evolutions of the droplet change in temperature $\left(T-T_{0}\right)$ and of the square diameter normalized by its value $D_{0}$ at the first measurement are shown in Figs. 3 and 4. In both cases, significant differences can be observed among the plotted curves. Regarding the square diameter, in the case of decane and dodecane, evaporation does not compensate for the thermal expansion of these two fuels. For the other fuels (acetone, ethanol, 3-pentanone and $n$ heptane), the square diameter follows approximately a linear trend. The evaporation rate $K$ (slope of $D^{2}$ ) increases with the product volatility (Fig. 3 ). The $D^{2}$ evolutions are perfectly correlated with the boiling temperatures of the fuels (acetone: $56.5^{\circ} \mathrm{C}$, ethanol: $78.5{ }^{\circ} \mathrm{C}$, heptanes: $98.5^{\circ} \mathrm{C}, 3$-pentanone: $101{ }^{\circ} \mathrm{C}, n$-decane: $174^{\circ} \mathrm{C}, n$-dodecane: $216^{\circ} \mathrm{C}$ ). Conversely, the droplet heating is less important when increasing the fuel volatility (Fig. 4). This behaviour can be attributed to the increase of the heat flux due to vaporization $\Phi_{\text {vap }}$ which is taken to the detriment of the heat flux entering into the droplet $Q_{L}$ (see the heat conservation equation Eq. (1)).

Table 1

Conditions at the first measurement point in the heated enclosure for the droplet stream.

\begin{tabular}{llclll}
\hline Fuel & $D_{0}(\mu \mathrm{m})$ & $V_{0}(\mathrm{~m} / \mathrm{s})$ & $T_{0}\left({ }^{\circ} \mathrm{C}\right)$ & $C_{0}$ & $f(\mathrm{kHz})$ \\
\hline Acetone & 122.6 & 10.6 & 26.1 & 4.43 & 20,900 \\
Ethanol & 119.6 & 9.01 & 29.7 & 4.53 & 19,450 \\
Heptane & 129.3 & 11.8 & 28.6 & 4.42 & 22,800 \\
3-Pentanone & 121.2 & 10.1 & 28.8 & 4.8 & 18,288 \\
Decane & 121.5 & 10.8 & 26.6 & 4.4 & 20,800 \\
Dodecane & 110 & 8.12 & 29.6 & 4.48 & 19,440 \\
\hline
\end{tabular}

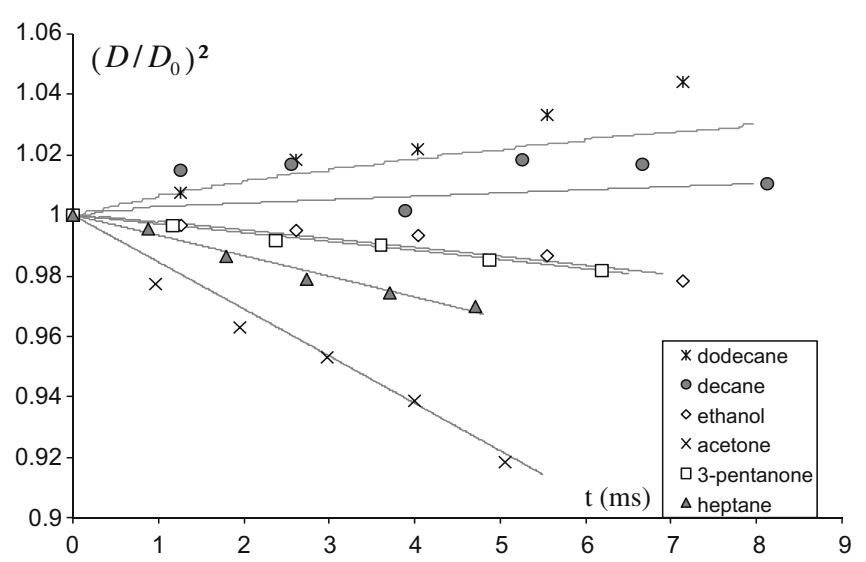

Fig. 3. Time evolution of the normalized square diameter for the different droplet streams (dots: experimental data, lines: simulations resulting from the inversion procedure) (initial conditions given in Table 1 ).

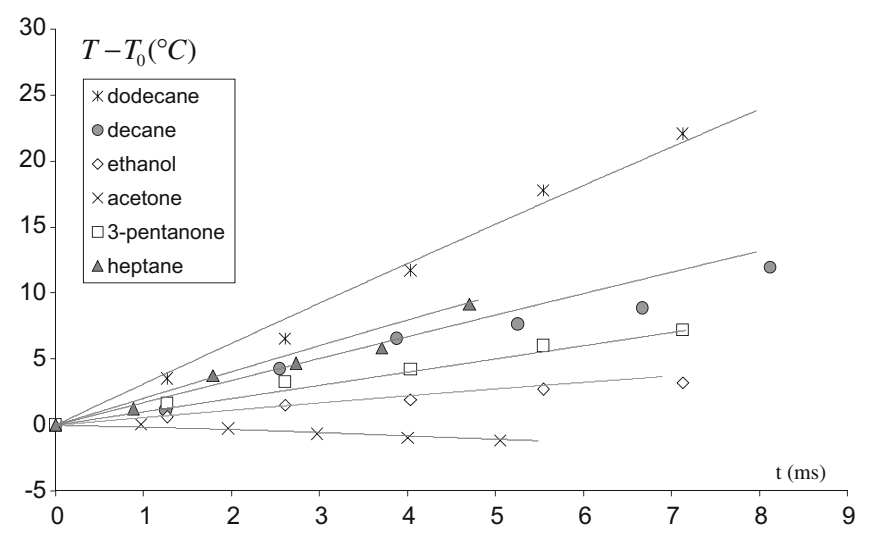

Fig. 4. Time evolution of the droplet variation in temperature (dots: experimental data, lines: simulations resulting from the inversion procedure) (initial conditions given in Table 1).

Since the evaporation has a cooling effect, the temperature of an evaporating droplet stabilizes below the boiling point even in overheated ambient gases. The wet bulb temperature corresponds to the steady state temperature achieved during the evaporation [29]. In the case of acetone, the wet bulb temperature is slightly lower than the injection temperature $\left(25^{\circ} \mathrm{C}\right)$ at $T_{a m b}=370^{\circ} \mathrm{C}$. This explains the limited but continuous cooling of the acetone in Fig. 4.

\section{Characterization of the Nusselt and Sherwood numbers}

The case of a moving evaporating droplet is considered in this section. The radiation exchanges are neglected, which is justified by the moderate ambient temperature within the enclosure less than $400^{\circ} \mathrm{C}$. Assuming that the local heat fluxes at the droplet surface are uniformly distributed, the overall energy balance of the evaporation can be summarized as followed:

$Q_{L}=\Phi_{C}-\Phi_{v a p}$

where $Q_{L}$ is the heat flux entering into the droplet, $\Phi_{C}$ is the convective heat flux transferred from the gas phase and $\Phi_{\text {vap }}$ is the heat flux due to vaporization defined by:

$\Phi_{\text {vap }}=-L_{v} \dot{m}$

$Q_{L}$ is evaluated from the energy conservation [15]. 
$Q_{L}=m C_{p l} \frac{d T_{m}}{d t}+C_{p l}\left(T_{S}-T_{m}\right) \dot{m}$

where $T_{m}$ is the mean droplet temperature.

Both convective and vaporization fluxes $\Phi_{C}$ and $\Phi_{v a p}$ can be derived from Nusselt and Sherwood numbers:

$\Phi_{c}=\pi \lambda_{g} D N u\left(T_{a m b}-T_{S}\right)$

$\Phi_{\text {vap }}=\dot{m} L_{v}=L_{v} \pi \rho_{g} D D_{g} B_{M} S h$

where $B_{M}$ is the Spalding mass transfer number defined by: $B_{M}=\left(Y_{S}-Y_{a m b}\right) /\left(1-Y_{S}\right)$.

The fuel vapour mass fraction $Y_{S}$ is determined assuming a liquid-vapour equilibrium at the droplet surface. The fuel vapour molar fraction at the droplet surface is then $\chi_{S}=P_{\text {sat }}\left(T_{S}\right) / P$, where $P_{s a t}$ denotes the saturation pressure of the fuel. $\chi_{S}$ is related to $Y_{S}$ by $Y_{S}=\chi_{s} M_{v} /\left(\chi_{s} M_{v}+\left(1-\chi_{s}\right) M_{\text {air }}\right)$ where $M_{v}$ and $M_{\text {air }}$ are, respectively, the molar mass of the vapour and the air. In Eqs. (4) and (5), the gas properties $\rho_{g}, D_{g}, \lambda_{g}$ should be estimated at a reference state according to the ' $1 / 3$ rule' $[30]$.

From Eqs. (1)-(5), it appears that an experimental characterization of the Nusselt and Sherwood numbers, would require to know the droplet mass, its surface and volume averaged temperatures as well as the time evolutions of these parameters. The main difficulty to estimate the Nusselt and Sherwood numbers relates to the fact that the surface temperature $T_{S}$ is not directly measured. The surface temperature lies between the average temperature and the wet bulb temperature. Since the measurements correspond to the beginning of the transient heating phase, it is likely be closer to $T_{m}$. However, this leaves too much uncertainty about the value of this parameter. Therefore, the surface temperature has to be estimated by an inversion model. A step-by-step procedure has been implemented to determine the Nusselt and Sherwood numbers. As an initial guess value for the calculations, $T_{S}(t)$ is assumed to be equal to the volume averaged temperature of the droplet $T_{m}(t)$.

Step 1: The experimental droplet diameter is corrected from the density change due to the thermal expansion of the droplet.

$$
D_{\text {corr }}=D\left(\rho\left(T_{m}\right) / \rho\left(T_{m, t=0}\right)\right)^{1 / 3}
$$

This correction is required for fuels having a low volatility. As shown in Fig. 3, the droplet size may increase due to thermal expansion. Assuming the 'D2-law', the evaporation rate $K$ can be determined by the least mean square method from the experimental data:

$D_{\text {corr }}^{2}(t)=D_{\text {corr }}^{2}(t=0)-K t$

The mass vapour flowrate is then given by:

$\dot{m}=-\frac{\pi}{4} \rho_{l}\left(T_{t=0}\right) D_{\text {corr }}(t) K$

The assumption of a constant evaporation rate is questionable since it is known that the evaporation rate of an isolated droplet is a function of the surface conditions $\left(T_{S}, Y_{S}\right)$ that vary over the time. However, this approximation is supported by experimental results which show an almost linear trend of $D^{2}$ (Fig. 3).

Step 2: The time derivative of the temperature $d T_{m} / d t$ is calculated from a fitted curve interpolating the temperature measurement. As observed in Fig. 4, a linear interpolation is satisfactory because measurements concern a limited period of the heating phase.

Step 3: Physical properties of $\rho_{g}, D_{g}, \lambda_{g}$ are calculated according to the $1 / 3$ rule.

Step 4: Sherwood number is derived from Eqs. (5) and (8).
Step 5: $Q_{L}$ is estimated using Eq. (3). From the energy conservation (Eq. (1)), it is possible to determine the value of the convective heat flux $\Phi_{C}$ and thus the Nusselt number using Eq. (4).

Step 6: The evolutions of the droplet size and temperature are then simulated using the values of Nusselt and Sherwood numbers found in steps 4 and 5 . The simulation is carried out assuming as an initial condition, a uniform temperature field equal to the value measured at the first measurement position. The same numerical approach (including the boundary condition) as described by Abramzon and Sirignano [2] is used, except that Nusselt and Sherwood numbers are presently known in advance. The heat diffusion equation is solved by a Crank-Nicholson scheme.

$$
\frac{\partial T}{\partial t}-\frac{\xi}{R} \frac{d R}{d t} \frac{\partial T}{\partial \xi}=\frac{\alpha_{l, e f f}}{\xi^{2} R^{2}} \frac{\partial}{\partial \xi}\left(\xi^{2} \frac{\partial T}{\partial \xi}\right), \quad 0 \leq \xi \leq 1
$$

Eq. (9) accounts for the convection due to internal circulation by the use of the effective thermal diffusivity $\alpha_{l, e f f}=\chi \alpha_{l}$ where the coefficient $\chi$ varies from about 1 (at droplet Peclet number $<10$ ) to 2.72 (at droplet Peclet number $>500$ ) [2]. A time step equal to $0.01 \mathrm{~ms}$ is taken to solve Eq. (9). At each time step of this resolution, the value of $T_{S}$ is updated so that $\left.4 \pi R^{2} \lambda_{l} \frac{d T}{d r}\right) \quad=-Q_{L}$. The value of $Q_{L}$ is determined from Eqs. (1), (4), and $\left.{ }^{r} \bar{t}^{R}\right)$ and is function of the Nusselt and Sherwood numbers.

Step 7: An estimated evolution of the surface temperature is deduced from step 6 , then calculation returns to step 3 . The iterative procedure is stopped when Nusselt and Sherwood numbers converge with an error less than $1 \%$. Generally, 3 or 4 iterations are required to fulfil this condition.

Interpolations in steps 1 and 2 ensure that the temperature and diameter simulated in step 6 are close to their experimental counterparts whatever the convergence of Nusselt and Sherwood numbers. As an example, the simulated temperature and diameter are superimposed on the measurements in Figs. 3 and 4.

An important issue concerns the uncertainties in the estimate of the Nusselt and Sherwood numbers. The variations of the droplet size and temperature are sometimes not enough important to determine those numbers with a sufficient accuracy. For instance, in the case of $n$-decane and $n$-dodecane, the very low evaporation makes that the inversion procedure fails to obtain reliably the Sherwood number: there is almost no sensitivity to this parameter. On the other hand, the Nusselt number can be evaluated correctly since $Q_{L}$ is dominant to $\Phi_{\text {vap }}$ in these cases. With the exception of the Sherwood number for $n$-decane and $n$-dodecane, it was possible to determine the Nusselt and Sherwood numbers in all other cases and to specify their uncertainties. Knowing the uncertainties in the measurement of the droplet size $( \pm 0.5 \mu \mathrm{m})$ and temperature $\left( \pm 1^{\circ} \mathrm{C}\right)$, a lower and an upper bound for the estimate of $d D^{2} / d t$ and $d T_{m} / d t$ can be inferred. These values are then entered in the inversion procedure so as to obtain bounding values of Nusselt and Sherwood numbers. Table 2 summarizes all the measurements; depending on the fuel and the experimental conditions, experimental uncertainties can vary between $2 \%$ and $25 \%$.

\section{Discussion and results}

Quantifying the effects of the interactions on the heat and mass transfer is difficult, since the Nusselt and Sherwood numbers depend on many parameters such as the Reynolds, Prandtl, Schmidt and Spadling numbers. A simple method consists in comparing the obtained values of the Nusselt and Sherwood numbers to their counterparts for an isolated droplet since theoretical models already exist and have been assessed in this particular case. In a 
Table 2

List of all the performed measurements including time-averaged Nusselt and Sherwood numbers with their respective uncertainties.

\begin{tabular}{|c|c|c|c|c|c|c|c|c|c|}
\hline Fuel & $D_{0}(\mu \mathrm{m})$ & $V_{0}(\mathrm{~m} / \mathrm{s})$ & $T_{0}\left({ }^{\circ} \mathrm{C}\right)$ & $C_{0}$ & $f(\mathrm{kHz})$ & $\mathrm{Nu}$ & $\frac{\Delta N u}{N u}$ & $S h$ & $\frac{\Delta S h}{S h}$ \\
\hline \multirow[t]{3}{*}{ Acetone } & 130.2 & 6.5 & 24.1 & 3.3 & 20,800 & 1.139 & 11.2 & 1.24 & 10.9 \\
\hline & 119.6 & 10.6 & 26 & 4.53 & 20,900 & 2.15 & 9.3 & 2.54 & 7 \\
\hline & 112.4 & 13.3 & 25.5 & 5.5 & 20,800 & 2.34 & 9.5 & 2.37 & 8.5 \\
\hline \multirow[t]{3}{*}{ Ethanol } & 130.2 & 11.8 & 29.8 & 6.1 & 18,555 & 1.885 & 11 & 5.4 & 10.8 \\
\hline & 119.6 & 9 & 29.7 & 4.5 & 19,450 & 0.77 & 23 & 1.84 & 25 \\
\hline & 112.4 & 6.2 & 29.1 & 3.05 & 20,563 & 1.25 & 10 & 3.4 & 11 \\
\hline \multirow[t]{3}{*}{ Heptane } & 131 & 11.8 & 28.6 & 5.3 & 22,800 & 1.62 & 12.2 & 6.3 & 14.5 \\
\hline & 122.8 & 9.6 & 26.8 & 3.75 & 22,700 & 0.92 & 12 & 2.2 & 24 \\
\hline & 134.4 & 14.3 & 28.1 & 4.53 & 21,900 & 1.535 & 10 & 4 & 15 \\
\hline \multirow[t]{2}{*}{ 3-Pentanone } & 121.3 & 8.7 & 28.8 & 4 & 20,300 & 0.65 & 15 & 2.43 & 16 \\
\hline & 118.2 & 10 & 29 & 4.8 & 18,290 & 0.6 & 14 & 3.7 & 13 \\
\hline \multirow[t]{3}{*}{ Decane } & 128.3 & 10.8 & 27 & 4.4 & 20,800 & 0.96 & 12 & & \\
\hline & 124.8 & 12.6 & 27.2 & 5.4 & 18,500 & 0.76 & 20 & & \\
\hline & 119.1 & 5.6 & 31.5 & 3 & 18,500 & 0.99 & 12 & & \\
\hline \multirow[t]{3}{*}{ Dodecane } & 99 & 5.6 & 30.3 & 3 & 22,500 & 0.79 & 3 & & \\
\hline & 129 & 11.4 & 29.3 & 6.9 & 15,150 & 0.88 & 2 & & \\
\hline & 110 & 8.1 & 30 & 4.4 & 19,440 & 0.87 & 2.8 & & \\
\hline
\end{tabular}

quasi-steady approach of the evaporation, according to the film theory [2], the expressions of the Nusselt and Sherwood numbers of an isolated evaporating moving droplet are given by:

$N u_{\text {iso }}=\frac{\ln \left(1+B_{T}\right)}{B_{T}}\left(2+\frac{N u_{0}-2}{F\left(B_{T}\right)}\right)$

$S h_{\text {iso }}=\frac{\ln \left(1+B_{M}\right)}{B_{M}}\left(2+\frac{S h_{0}-2}{F\left(B_{M}\right)}\right)$

$N u_{0}$ and $S h_{0}$ correspond to the Nusselt and Sherwood numbers without the presence of the Stefan flow. Abramzon and Sirignano [2] suggest the use of the following correlations by Clift et al. [31]:

$N u_{0}=1+(1+\operatorname{RePr})^{1 / 3} f(\operatorname{Re})$

$S h_{0}=1+(1+R e S c)^{1 / 3} f(R e)$

with $f(R e)=1$ at $R e \leqslant 1$ and $f(R e)=R e^{0.077}$ at $R e \leqslant 400$.

$F(B)$ is a function introduced by Abramzon and Sirignano [2]. $F(B)=(1+B)^{0.7} \ln (1+B) / B$ which should be applied in order to account for the effect of Stefan flow on the evaporation, since the fuel vapour flow tends to modify the convective transport around the droplet.

In Eq. (10), $B_{T}$ denotes the heat transfer Spalding number defined as:

$B_{T}=\frac{C p_{g}\left(T_{a m b}-T_{S}\right)}{L_{v}+Q_{L} / \dot{m}}$

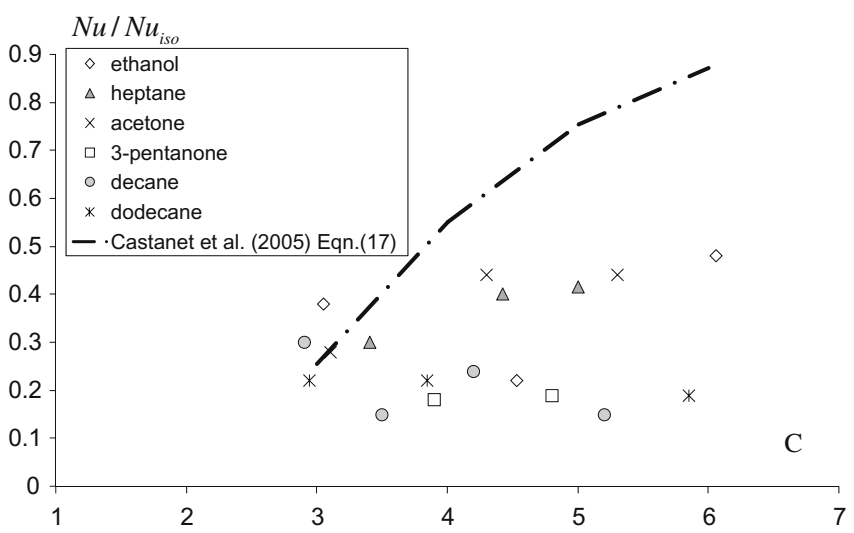

Fig. 5. Normalized Nusselt number $\mathrm{Nu} / \mathrm{Nu}_{\mathrm{iso}}$ as a function of the distance parameter $C$.

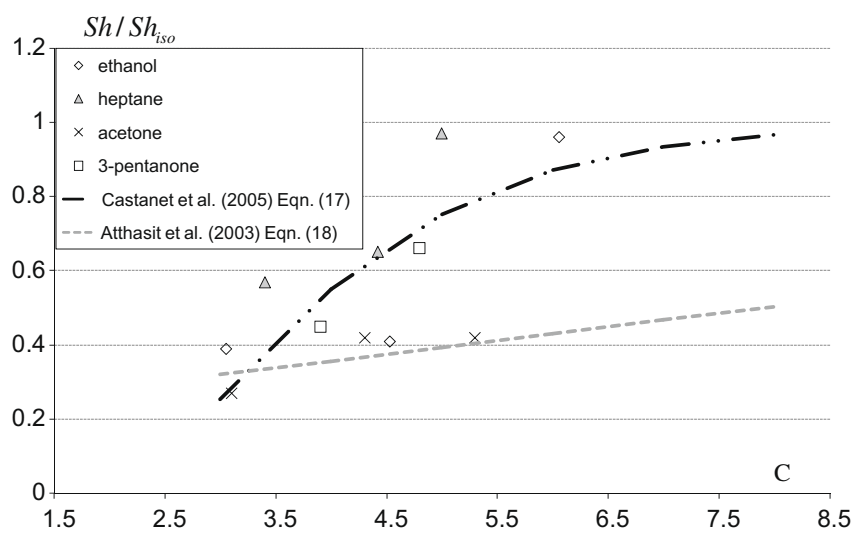

Fig. 6. Normalized Sherwood number Sh/Shiso as a function of the distance parameter $C$.

$\mathrm{Nu} / \mathrm{Nu}$ iso and $\mathrm{Sh} / \mathrm{Sh}_{\text {iso }}$ are depicted in Figs. 5 and 6 as a function of the dimensionless spacing parameter $C$ for all the tested conditions:

$C=V /(f D)$

On these two figures, each experiment is represented by a scatter of points because of the temporal variation of the parameters $C$, $\mathrm{Nu}, \mathrm{Sh}, \mathrm{B}_{M}$ and $\mathrm{B}_{T}$. Nevertheless, there is in general little variation of Nusselt and Sherwood on the time interval corresponding to the measurements. The Sherwood number cannot be determined for the very low volatile fuels ( $n$-decane and $n$-dodecane). A relatively large dispersion of the experimental data can be observed for both Nusselt and Sherwood numbers between the experiments. No clear trend can be highlighted: the distance parameter $C$ does not appear sufficient to describe the effects of interactions for fuels having different volatilities. Data can be compared to the results of Castanet et al. [15] and Atthasit et al. [17]. They studied the case of ethanol droplets evaporating in a flame [15] or in the thermal boundary layer of a heated plate. To account for interactions, both authors suggested a correlation depending only on the distance parameter $C$.

According to Castanet et al. [15]:

$\frac{N u}{N u_{\text {iso }}}=\frac{S h}{S h_{\text {iso }}}=\eta(C)$

$\eta(C)=\tanh (0.36 C-0.82), \quad C \geq 3$ 
and according to Atthasit [17]:

$$
\frac{S h}{S h_{\text {iso }}}(C)=1-0.57\left[1-\frac{1-\exp (-0.13(C-6))}{1+\exp (-0.13(C-6))}\right]
$$

However, their results were limited to the case of ethanol and were obtained at higher ambient temperatures. Moreover, comparison of Figs. 5 and 6 highlights that $N u / N u_{\text {iso }}$ and $S h / S h_{\text {iso }}$ can have quite different values, which was not observed by Castanet et al. [15] in the case of ethanol droplets. To describe the effects of droplets interactions in term of heat and mass transfer, it is interesting to compare the time between two consecutive drops and the characteristic time of heat or mass diffusion through the diffusion film introduced by Abramzon and Sirignano [2]. The thickness of this film takes into account the influence of forced convection on the transfer. The dimensionless time $t^{*}$ formed from the ratio of these times is:

$t^{*}=\frac{\delta f}{V_{r}}$

In this expression, $\delta$ denotes the film thickness as defined in the film theory [2]. It has a different value in the case of the heat and mass transfer:

$\delta_{M}=D \frac{F_{M}}{S h_{0}-2}$

$\delta_{T}=D \frac{F_{T}}{N u_{0}-2}$

$V_{r}$ is the radial velocity of the vapour around the droplet surface due to the Stefan flow:

$V_{r}=\frac{\dot{m}}{4 \pi \rho_{g} R^{2}}$

The characteristic time $\left(\delta / V_{r}\right)$ was formerly introduced by Gokalp et al. [32] and Wu et al. [33], to describe the effect of turbulence on the evaporation rate. The Stefan flow velocity $V_{r}$ and the film diffusion thickness in the expression of $t^{*}$ are used to encompass the influence of fuel volatility on the effect of heat and mass transfer interactions. The value of $t^{*}$ is the most important for the less volatile product. Indeed a low volatility corresponds to a high resistance to the transfer (high value of $\delta$ ) and a small vapour velocity $V_{r}$. Additionally, $t^{*}$ decreases when increasing the frequency of the droplets, which is consistent with the dependence on the distance parameter $\mathrm{C}$ already ascribed in previous studies [15,17]. $\mathrm{Nu} / \mathrm{Nu}$ iso and $\mathrm{Sh} / \mathrm{Sh}$ iso are plotted as a function of $t^{*}$ in Fig. 7. The uncertainties on $t^{*}, \mathrm{Sh} /$ Shiso and $\mathrm{Nu} / \mathrm{Nuiso}$ have been added (see Table 2). This uncertainty on the evaluation of $t^{*}$ comes from the film thickness $\delta$ and the Stefan flow velocity $V_{r}$, which are particularly inaccurate for the very low volatile fuels, i.e. $n$-decane and $n$-dodecane. Contrary to the previous representations with the distance parameter (Figs. 5 and 6), a

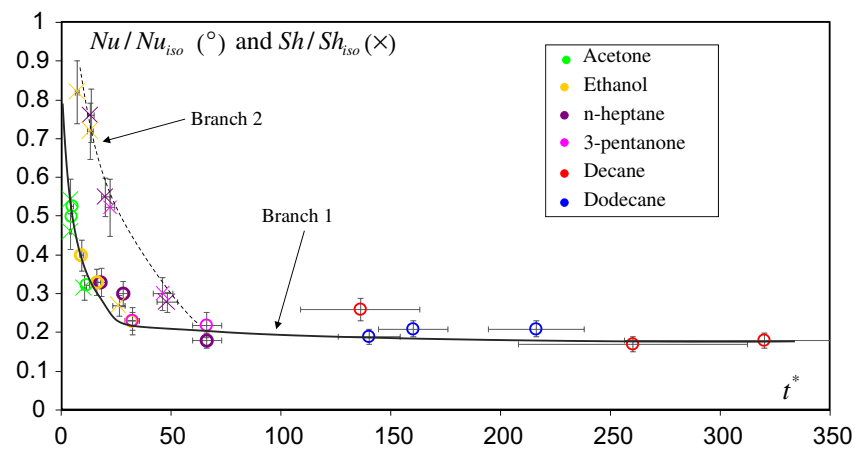

Fig. 7. $\mathrm{Nu} / \mathrm{Nu}_{\text {iso }}$ and $\mathrm{Sh} / \mathrm{Sh}_{\text {iso }}$ as a function of the dimensionless time $t^{*}$. Identification of the two branches given in Eq. (23). clear trend can be found. It can be noticed that an increase of $t^{*}$ tends to reduce $\mathrm{Nu} / \mathrm{Nu} u_{\text {iso }}$ and $\mathrm{Sh} / \mathrm{Sh}_{\text {iso. }}$. A low volatility and a high frequency of the droplets are factors that increase the effect of interactions on heat and mass transfer. From Fig. 7, it is possible to group the data into two sets of points each forming a branch. The first branch corresponds to $\mathrm{Nu} / \mathrm{Nu}$ iso of each fuel and $\mathrm{Sh} / \mathrm{Sh} h_{\text {iso }}$ of acetone. The second branch is formed by $S h / S h_{\text {iso }}$ of ethanol and $n$-heptane. An equation can be given to these two branches:

$\eta\left(t^{*}\right)=\frac{1-A}{\left(B t^{*}+1\right)^{C}}+A$

where $A=0.155335, B=1.416767, C=0.535026$ for branch 1 and $A=0.155335, B=6.503406 \times 10^{-7}, C=54302.36$ for branch 2 , the domain of validity corresponding to $t^{*} \leqslant 50$.

The existence of these two branches suggests that $t^{*}$ is probably not sufficient to account for all the effects observed experimentally. For instance, it can be noticed that ethanol and $n$-heptane droplets have a mass transfer Spalding number $B_{M}$ particularly small compared to those of acetone ( 0.2 for ethanol and $n$-heptane, 1 for acetone), which suggests a possible residual effect of the Spalding numbers, hence the existence of a second branch.

Finally, with some restrictions concerning its domain of application, Eq. (23) can be used to estimate the effect of interactions on the heat and mass transfer in monodisperse droplets streams. Simulations can be carried out as described in step 6 of the inversion process (Section 4) except that the calculations of Nusselt and Sherwood numbers are now based on Eq. (23). Results are presented for 3 products (acetone, ethanol and $n$-decane) in Fig. 8 for the droplet size reduction and in Fig. 9 for the droplet temperature evolution. In comparison in the same figures, the correlation of Castanet et al. [15] does not give satisfactory results even for ethanol. As previously mentioned this correlation accounts only for the effect of the distance parameter $C$. However, in the present study $C$ does not vary so much since the emphasis is placed on covering a large range of volatility with different fuels.

\section{Conclusion}

Non-intrusive optical techniques have been used to determine Sherwood and Nusselt numbers of interacting droplets that evaporate under controlled conditions in a monodisperse droplet stream. Fuels having different volatilities have been tested. The geometric arrangement of the droplets, the volatility of the fuel seem to play a decisive role on the way that heat and mass transfer are modified by the droplet interactions. To describe the experimental results, a

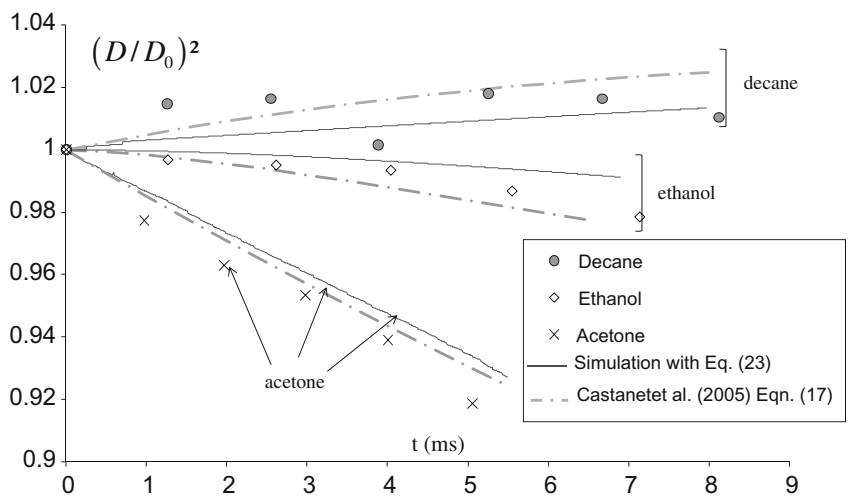

Fig. 8. Temporal evolution of the droplet size in the case of acetone $\left(V_{0}=10.6 \mathrm{~m} / \mathrm{s}\right.$, $\left.D_{0}=122.6 \mu \mathrm{m}, T_{0}=26^{\circ} \mathrm{C}\right)$, ethanol $\left(V_{0}=9 \mathrm{~m} / \mathrm{s}, D_{0}=119.6 \mu \mathrm{m}, T_{0}=29.7^{\circ} \mathrm{C}\right)$ and dodecane $\left(V_{0}=10.8 \mathrm{~m} / \mathrm{s}, D_{0}=121.5 \mu \mathrm{m}, T_{0}=30^{\circ} \mathrm{C}\right)$ evaporating droplet. Comparison between the experimental results and Eq. (23) and the existing correlations of Castanet et al. [15] (Eq. (17)). 


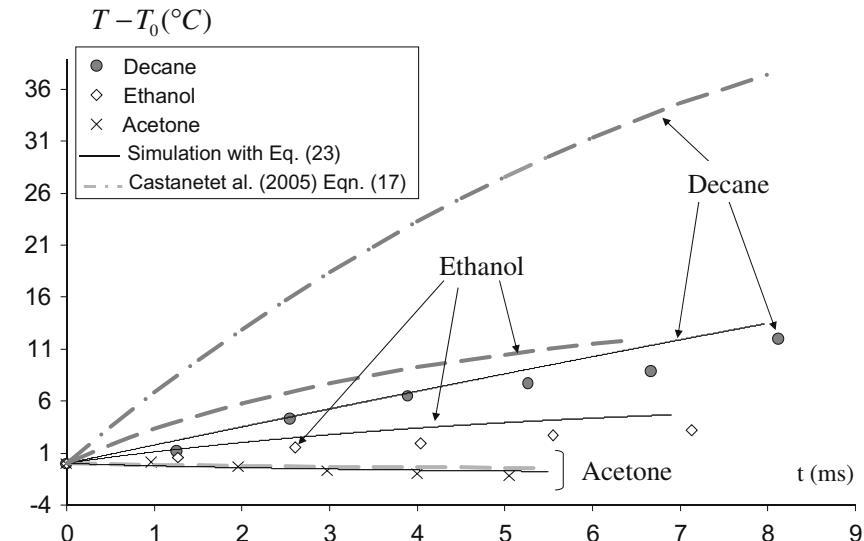

Fig. 9. Temporal evolution of the droplet temperature in the case $\left(V_{0}=10.6 \mathrm{~m} / \mathrm{s}\right.$, $\left.D_{0}=122.6 \mu \mathrm{m}, T_{0}=26{ }^{\circ} \mathrm{C}\right)$, ethanol $\left(V_{0}=9 \mathrm{~m} / \mathrm{s}, D_{0}=119.6 \mu \mathrm{m}, T_{0}=29.7^{\circ} \mathrm{C}\right)$ and dodecane $\left(V_{0}=10.8 \mathrm{~m} / \mathrm{s}, D_{0}=121.5 \mu \mathrm{m}, T_{0}=30^{\circ} \mathrm{C}\right)$ evaporating droplet. Comparison between the experimental results and Eq. (23) and the existing correlations of Castanet et al. [15] (Eq. (17)).

dimensionless parameter was introduced. It compares the time between two consecutive droplets and the characteristic time of diffusion through the diffusion film around the droplet which was introduced by Abramzon and Sirigano to take into account the forced convection. This parameter seems more appropriate to describe the experimental results than the distance parameter only, which considers only the geometric arrangement of the droplets.

\section{References}

[1] W.A. Sirignano, Fluid Dynamics and Transport of Droplets and Sprays, Cambridge University Press, 1999.

[2] B. Abramzon, W.A. Sirignano, Droplet vaporization model for spray combustion calculations, Int. J. Heat Mass Transfer 32 (1989) 1605.

[3] E.E. Michaelides, Hydrodynamic force and heat/mass transfer from particles, bubbles, and drops - the Freeman scholar lecture, ASME J. Fluid Eng. 125 (2003) 209-238.

[4] S.S. Sazhin, Advanced models of fuel droplet heating and evaporation, Prog. Energy Combust. Sci. 32 (2006) 162-214.

[5] M. Labowsky, Calculation of the burning rates of interacting fuel droplets, Combust. Sci. Technol. 22 (1980) 217-226.

[6] M. Marberry, A.K. Ray, K. Leung, Effect of multiple particle interactions on burning droplets, Combust. Flame 57 (1984) 237-245

[7] C.H. Chiang, W.A. Sirignano, Interacting, convecting, vaporizing fuel droplets with variable properties, Int. J. Heat Mass Transfer 36 (1993) 875.

[8] C.H. Chiang, W.A. Sirignano, Axisymmetric calculations of three droplet interactions, Atomization Sprays 3 (1993) 91.

[9] R.T. Imaoka, W.A. Sirignano, Vaporization and combustion in threedimensional droplet arrays, Proc. Combust. Inst. 30 (2005) 1981.

[10] R.T. Imaoka, W.A. Sirignano, Transient vaporization and burning in dense droplet arrays, Int. J. Heat Mass Transfer 48 (2005) 4354.

[11] A. Frohn, N. Roth, Dynamics of Droplets, Springer-Verlag, Berlin and Heidelberg GmbH, 2000.
12] J.J. Sangiovanni, A.S. Kesten, Effect of droplet interaction on ignition in monodispersed droplet streams, in: Sixteenth International Symposium on Combustion, The Combustion Institute, 1976.

[13] J.J. Sangiovanni, M. Labowski, Burning times of linear fuel droplet arrays: a comparison of experiment and theory, Combust. Flame 45 (1982) 15-30.

[14] J.F. Virepinte, Y. Biscos, G. Lavergne, P. Magre, G. Collin, A rectilinear droplet stream in combustion: droplet and gas phase properties, Combust. Sci. Technol. 150 (2000) 143.

[15] G. Castanet, M. Lebouché, F. Lemoine, Heat and mass transfer of combusting monodisperse droplets in a linear stream, Int. J. Heat Mass Transfer 48 (2005) 3261.

[16] G. Castanet, P. Lavieille, F. Lemoine, M. Lebouché, A. Atthasit, Y. Biscos, G. Lavergne, Energetic budget on an evaporating monodisperse droplet stream using combined optical methods, Eval. Convective Heat Transfer 45 (25) (2002) 5053-5067.

[17] Atthasit A, Doué N, Biscos Y, Lavergne G., Influence of droplet concentration on the dynamics and evaporation of a monodisperse stream of droplets in evaporation regime, in: First International Symposium on Combustion and Atmospheric Pollution, St-Petersburg, Russia, July 8-11, 2003.

[18] G. Castanet, C. Maqua, M. Orain, F. Grisch, F. Lemoine, Investigation of heat and mass transfer between the two phases of an evaporating droplet stream using laser-induced fluorescence techniques: comparison with modeling, Int. J. Heat Mass Transfer 50 (2007) 3670-3683.

[19] C. Maqua, G. Castanet, F. Grisch, F. Lemoine, T. Kristyadi, S.S. Sazhin, Monodisperse droplet heating and evaporation: experimental study and modeling, Int. J. Heat Mass Transfer 51 (2008) 3932-3945.

[20] C. Maqua, G. Castanet, F. Lemoine, Bicomponent droplets evaporation: temperature measurements and modeling, Fuel 87 (2008) 2932-2942.

[21] V. Deprédurand, C. Maqua, G. Castanet, F. Lemoine, Temperature measurement of evaporating ethanol/3-pentanone bicomponent droplets using 2-colour LIF, Institute for Liquid Atomization and Spray Systems, Mugla, Turkey, 2007.

[22] P. Lavieille, F. Lemoine, M. Lebouché, Investigation on temperature of evaporating droplets in a linear stream using two color laser induced fluorescence, Combust. Sci. Technol. 174 (2002) 117-142.

[23] G. Castanet, P. Lavieille, M. Lebouché, F. Lemoine, Measurement of the temperature distribution within monodisperse combusting droplets in linear stream using two colors laser-induced fluorescence, Exp. Fluids 35 (2003) 563-571.

[24] P. Lavieille, F. Lemoine, G. Lavergne, M. Lebouché, Evaporating and combusting droplet temperature measurements using two color laser induced fluorescence, Exp. Fluids 31 (2001) 45.

[25] V. Depredurand, P. Miron, A. Labergue, M. Wolff, G. Castanet, F. Lemoine, A temperature-sensitive tracer suitable for two-colour laser-induced fluorescence thermometry applied to evaporating fuel droplets, Meas. Sci. Technol. 9 (10) (2008)

[26] G. Koenig, K. Anders, A. Frohn, A new light scattering technique to measure droplet diameter of periodically generated moving droplets, J. Aerosol. Sci. 17 (1986) 157-167.

[27] P. Massoli, Rainbow refractometry applied to radially inhomogeneous spheres: the critical case of evaporating droplets, Appl. Optics 37 (1998) 3227-3235.

[28] G. Gréhan, G. Gouesbet, A. Naqwi, F. Durst, Particle trajectory effects in phase Doppler systems: computations and experiments, Part. Part. Syst. Charact. 10 (1993) 332-338.

[29] M.C. Yuen, L.W. Chen, On drag of evaporating liquid droplets, Combust. Sci. Tech. 14 (1976) 147-154.

[30] G.L. Hubbard, V.E. Denny, A.F. Mills, Droplet evaporation: effects of transients and variable properties, Int. J. Heat Mass Transfer 18 (1975) 1003.

[31] R. Clift, J.R. Grace, M.E. Weber, Bubbles, Drops and Particles, Academic Press, New York, 1978

[32] I. Goklap, G. Chauveau, O. Simon, X. Chesneau, Mass transfer from liquid fuel droplets in turbulent flow, Combust. Flame 89 (1992) 286-298.

[33] J.-S. Wu, Y.-J. Liu, H.-J. Sheen, Effects of ambient turbulence and fuel properties on the evaporation rate of single droplets, Int. J. Heat Mass Transfer 44 (2001) 4593-4603. 